\title{
Animal welfare and other ethical implications of Precision Livestock Farming technology
}

\author{
Juliette Schillings ${ }^{*} \mathbb{B}$, Richard Bennett and David Christian Rose
}

\begin{abstract}
In this commentary, we explore the risks and challenges associated with Precision Livestock Farming technologies based on an online workshop with over 70 international animal welfare experts, policy-makers, NGO, students, farmers and industry staff.
\end{abstract}

Keywords: Animal health, Animal welfare, Ethics, Precision livestock farming, Technology

The term Precision Livestock Farming (PLF) is generally associated with technologies that allow the real-time, automated and continuous monitoring of farmed animals (Berckmans 2017), such as cameras, sensors, and sound devices, which are increasingly powered by artificial intelligence and allow the collection and interpretation of data. They are seen as one of the promising solutions to sustainable livestock farming, helping farmers to improve productivity, whilst limiting environmental degradation, sustaining livelihoods and improving animal health and welfare. Whilst there has been considerable attention placed on the opportunities offered by PLF technologies, relatively less scholarly interest has been afforded to its risks (Werkheiser 2020).

Our efforts described below were inspired by a small number of research papers exploring the ethical implications of PLF (e.g., Bos et al. 2018; Werkheiser 2018, 2020), as well as research into the social and more-than-human consequences of robotic milking technologies (Bear and Holloway 2019; Hansen 2020; Vik et al. 2019). In order to identify the benefits and challenges of PLF in relation to animal welfare (and beyond) and how to address them, a

*Correspondence: j.schillings@pgr.reading.ac.uk School of Agriculture, Policy and Development, University of Reading, Earley, Reading RG6 6BZ, England major one-day online workshop gathering over 70 international animal welfare experts, policy-makers, NGO, students, farmers and industry staff was held in November 2020. A series of presentations and activities allowed the participants to discuss current developments in PLF for several species, their potential benefits to welfare, as well as the challenges and potential solutions. In this commentary, we focus specifically on the potential challenges and risks of PLF raised in this workshop and highlight areas for further research. These are summarized in Fig. 1 and discussed below.

\section{Technical limitations of PLF technologies}

In terms of technical limitations, the validation of PLF technologies was one of the main issues identified during the workshop. Technology validation is required to demonstrate that a system can meet its targets under realistic operating conditions. In the case of livestock farming where many variables must be taken into account, this means that the technology should be validated in different environments and conditions. Issues such as weather or location of animals may make data collection difficult (especially in extensive systems), as can internet access in rural locations. More generally, there are issues such as limited battery life or the structure of buildings which may not always be suited to the use of PLF technologies 


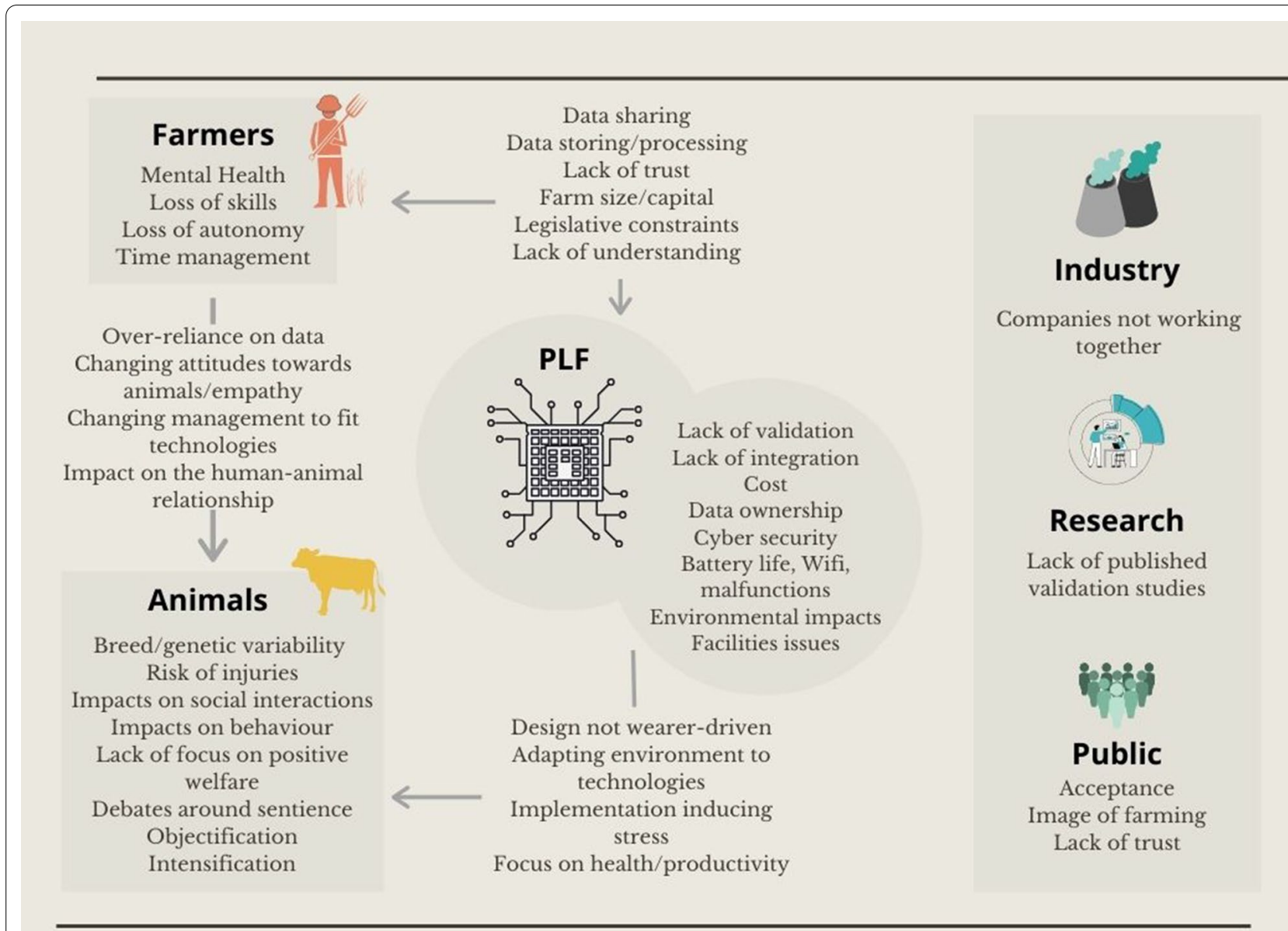

Fig. 1 A summary of the potential risks and challenges of Precision Livestock Farming technologies raised in the workshop

(e.g., difficulties to install cameras or presence of flies and dirty/wet conditions which could impact efficiency). Another important challenge relates to data integration. Thus far, most commercialised technologies operate 'individually' and do not communicate with each other. This means that each technology generates data relating to a specific parameter, which when accumulated could make it difficult for farmers to interpret and to make effective decisions based on those different results. Thus, more work is needed to demonstrate to farmers that the 'promise' of precision actually translates into practice (Kuch et al. 2020; Miles 2019).

\section{Challenges for farmers}

In the workshop, participants were concerned that many PLF technologies required significant investment from farmers, specialist knowledge and skills to operate or interpret data, advisory support (e.g., from veterinarians), and suitable farm infrastructure (e.g., broadband connectivity). Initial research has suggested that robotic milking technologies have tended to favour larger farms with the capacity both to invest (Yang et al. 2021) and access support. Studies focusing on adoption of general smart farming technologies acknowledge the importance of the factors raised above (Fielke et al. 2020; Klerkx et al. 2019), as well as trust which workshop participants also raised. Lack of farmer or advisor trust in the technologies may be linked to a lack of validation as well as information relating to cost-effectiveness. It may also relate to questions surrounding data ownership and how the data is used, stored and who is able to access it (Wiseman et al. 2019). This may in turn cause feelings of vulnerability, especially where cameras are working continuously. As large amounts of data are often stored on 'clouds', there are also concerns surrounding cyber security.

Workshop participants also raised questions about potential impacts on farmers' mental health linked to productivity and pressure to keep up with key performance indicators. Some farmers may not feel comfortable with the use of new technologies that may be difficult 
to understand and that require different sets of skills (Barrett and Rose 2020). Furthermore, there is the chance that PLF decreases animal keepers' contact with their animals, which could lead to negative welfare outcomes (see below), and reduced stockmanship skills (Butler and Holloway 2016; Werkheiser 2018). It was questioned whether PLF may also have an impact on farmers' autonomy, making them more dependent on external devices. Technologies could change what it means to be a farmer and make the job less attractive to some (Rose et al. 2018), though we acknowledge they could attract new workers to the industry.

\section{Animal welfare challenges}

Workshop participants emphasised the variability in production systems in terms of species, genetic variability and rearing environments, as well as individual variability in behaviours such as feeding or drinking. For this reason, devices that are not 'wearer-driven' or re-purposed for different species may not always be suitable; hence there is a potential that devices could cause physical injuries (e.g., due to the weight of a wearable sensor) or have impacts on animal behaviour (e.g., social behaviour), especially if a single animal is wearing multiple devices. There are also concerns that the implementation of PLF could change farm management to fit the use of technology rather than to improve welfare. For example, cameras may need longer and brighter light hours to work efficiently, or rearing environments may be made more barren to reduce obstacles or background noises for cameras.

Experts in the workshop pointed out that most PLF technologies appear to focus on productivity and health parameters and that while health is integral to welfare, other aspects (e.g., positive animal welfare) should also be taken into account. We also discussed whether the implementation of PLF would result in farmers spending less time with their animals, which could have an impact on the human-animal relationship and perhaps even changing human attitudes towards animals (Butler and Holloway 2016; Bear and Holloway 2019). This is in turn may lead to more ethical challenges such as the objectification of animals and further intensification, as PLF can help farmers monitor larger numbers of animals (Werkheiser 2018; Miles 2019).

\section{Consumer attitudes}

Experts in the workshop argued that consumer acceptance is an important aspect of responsible innovation and successful introduction of technologies (see Siegrist 2020). When it comes to food, consumers are often concerned about 'naturalness', which is also the case for people's perception of animal welfare (Koyratty et al. 2014; Schuppli et al. 2014). For this reason, workshop participants wondered whether a more digitalized, hightech, and 'faceless' version of farming would be acceptable to the consumer.

\section{Overcoming the challenges}

In our workshop, we also discussed how to address the technical, social, welfare, and consumer challenges raised above. Experts raised the following points:

- Technologies must be wearer-driven (considering genetic variability, breeds, rearing environment, welfare needs) and co-designed in consultation with multiple stakeholders, including the farmer to improve on-farm relevance and suitability;

- More funding/research is needed on technology validation; data integration; the added value of PLF; implications for animal welfare (assessment parameters, positive welfare, benefits of PLF); consumer acceptance; and farmer engagement;

- A code of practice is needed, developed in collaboration with farmers on data ownership/storing/ sharing/privacy, to increase transparency and trust;

- Technologists need to engage with other stakeholders: consumers, veterinarians, milk buyers, retailers, etc. at an early stage: educate, raise awareness and promote discussion;

- Accessible (cost, location, appropriate format) training needs to be provided to farmers to facilitate use of technologies and ensure technical assistance is provided;

- Support is needed to enable farmers to adopt technologies, including rural infrastructure, incentives to adopt, and advisory support.

We argue that whilst further efforts are needed to improve the scientific sophistication of PLF technologies, the research community, policy-makers, and funders alike need to place a greater emphasis on the ethical implications of their use. This will require a trans-disciplinary effort and a systems perspective, involving farmers, advisors, researchers and technologists in co-creation, rather than relying on 'technology push.

\section{Acknowledgements}

We thank Poppy Statham and Auvikki de Boon for help in organising the workshop as well as participants and speakers.

\section{Authors' contributions}

Conceptual work: JS led with support from DCR and RB; Review work: JS; Manuscript drafting: JS led with support from DCR and RB. All authors read and approved the final manuscript. 


\section{Funding}

The workshop was funded by the Animal Welfare Research Network (AWRN). AWRN is funded by BBSRC (BB/S012974/1) and UFAW. JS'PhD is funded by the Elizabeth Creak Charitable Trust, who also fund DCR.

\section{Availability of data and materials}

A summary of the workshop's results was made available to the Animal Welfare Research Network and can be accessed by members of this group.

\section{Declarations}

\section{Ethics approval and consent to participate}

When registering to be part of the workshop, participants submitted their consent to participate and were made aware that discussions could be used in subsequent reports or publications before they finalised their confirmation and consent.

\section{Competing interests}

There are no competing interests.

Received: 15 February 2021 Accepted: 21 April 2021

Published online: 10 May 2021

\section{References}

Barrett H, Rose DC. Perceptions of the fourth agricultural revolution: What's In, What's Out, and What Consequences are Anticipated? Sociol Rural. 2020. https://doi.org/10.1111/soru.12324.

Bear C, Holloway L. Beyond resistance: Geographies of divergent more-than human conduct in robotic milking. Geoforum. 2019;104:212-21.

Berckmans D. General introduction to precision livestock farming. Anim Front. 2017;7(1):6-11.

Bos JM, et al. The quantified animal: precision livestock farming and the ethical implications of objectification. Food Ethics. 2018;2(1):77-92.

Butler D, Holloway L. Technology and restructuring the social field of dairy farming: hybrid capitals, 'stockmanship' and automatic milking systems. Sociol Rural. 2016;56(4):513-30.

Fielke $\mathrm{S}$, et al. Digitalisation of agricultural knowledge and advice networks: a state-of-the-art review. Agric Syst. 2020;180:102763.
Hansen BG, et al. Automatic milking systems and farmer wellbeing-exploring the effects of automation and digitalization in dairy farming. J Rural Stud. 2020;80:469-80.

Klerkx L, et al. (2019). A review of social science on digital agriculture, smart farming and T agriculture 4.0: new contributions and a future research agenda. NJAS - Wageningen Journal of Life Sciences, 90-91, 100315.

Koyratty BNS, et al. Food additive control: A survey among selected consumers and manufacturers. British Food J. 2014;116(2):353-72.

Kuch $D$, et al. The promise of precision: datafication in medicine, agriculture and education. Policy Studies. 2020;41:527-46.

Miles $C$. The combine will tell the truth: On precision agriculture and algorithmic rationality. Big Data Soc. 2019;6(1):1-12.

Rose DC, et al. Exploring the spatialities of technological and user re-scripting: the case of decision support tools in UK agriculture. Geoforum. 2018;89:11-8.

Siegrist M, Hartmann C (2020) Consumer acceptance of novel food technologies. Nature Food 1(6):343-350

Schuppli CA, et al. Access to pasture for dairy cows: Responses from an online engagement'. J Anim Sci. 2014;92(11):5185-92.

Vik J, et al. (2019). The political robot - The structural consequences of automated milking systems (AMS) in Norway. NJAS - Wageningen Journal of Life Sciences, 90-91: 100305.

Werkheiser I. Precision livestock farming and farmers' duties to livestock. J Agric Environ Ethics. 2018;31(2):181-95.

Werkheiser I. Technology and responsibility: a discussion of underexamined risks and concerns in Precision Livestock Farming. Anim Front. 2020;10(1):51-7.

Wiseman, L. et al. (2019) Farmers and their data: An examination of farmers' reluctance to share their data through the lens of the laws impacting smart farming. NJAS-Wageningen Journal of Life Sciences. Elsevier, 90-91(December 2018), 100301.

Yang W, et al. Analysis of adoption trends of in-parlor technologies over a 10-year period for labor saving and data capture on pasture-based dairy farms. J Dairy Sci. 2021;104(1):431-42.

\section{Publisher's Note}

Springer Nature remains neutral with regard to jurisdictional claims in published maps and institutional affiliations.
Ready to submit your research? Choose BMC and benefit from:

- fast, convenient online submission

- thorough peer review by experienced researchers in your field

- rapid publication on acceptance

- support for research data, including large and complex data types

- gold Open Access which fosters wider collaboration and increased citations

- maximum visibility for your research: over $100 \mathrm{M}$ website views per year

At $\mathrm{BMC}$, research is always in progress.

Learn more biomedcentral.com/submissions 